\title{
Specific Elements of the Strategic Advantages of the Official and Working Languages in the International Community
}

\author{
Boris Mijović, PhD \\ Assistant Professor \\ Faculty for Business Economy Bar \\ Montenegro \\ Filip Turčinović PhD \\ Professor \\ Public University in Banja Luka and FPIM Univerzitet \\ Serbia
}

\begin{abstract}
There has been a common attitude in the theory on diplomatic relations referring to the fact that whatever the diplomats write in the course of their work, is due to be clear and precise. Each word, along with its context is due to be considered in order not to cause vagueness or confusion. This bears a significant importance in case of diplomatic relations being tense or being beyond the usual discourse. A style and a language used in diplomatic intercourse have numerous specific features. For that reason, some authors admit the existence of a special diplomatic style and language with its inevitable elegance, specific lexicon, idioms and phraseology. Still, we could hardly accept the attitude of a diplomatic language existing as a separate linguistic phenomenon. Thereat, we are to bear in mind a specific terminology to be due to the fact a great number of literary people, writers, scientists, writers along with many other admirers of tended written and spoken words, to have actively been involved in diplomatic business and to have been introducing beauty and virtuosity of literary words into diplomacy. Their contribution to the values of that style is enormous despite the existing tendency of diplomacy simplification and deformalisation. For the sake of attaining clarity, decent, considered, concise, adequate and undeniable conveyance of foreign messages, especially between subjects and decision making factors in the international community, diplomatic style and language make an obligatory element and a necessary instrument of such communication.
\end{abstract}

Keywords: diplomatic style, diplomatic language, clarity, conciseness, message, confusion, idiom, lexicon.

\section{Diplomatic Style}

Being governed by the principle of sovereign equality of countries, the fact of the countries being obliged to mutually respect and appreciate each other is undeniable. It implies, among other things, civilized intercourse and communication. Immediate participants in diplomatic relations are, according to the stated principles and rules, due to be courteous and very considerate in their behavior and performance. Considering the fact of the communication being conducted among the countries along with the fact of the principle of sovereign equality of countries in the international relations, simply meaning that the countries are equal, two features of diplomatic style are necessary to emphasize, them being courtesy and clarity .The lack of those two principles in an intercourse may cause unwanted consequences. Let's say, a receipt of a writ might be rejected due to the lack of a courteous style of addressing. The courteous style of addressing is due to be implied even in circumstances which require conveyance of unpleasant facts. ${ }^{1}$ Diplomatic style is ranked in the category of functional sub-styles along with literary and artistic, administrative and legal, publicist, scientific, conversational and others. The written diplomatic correspondence belongs to the legal and administrative sub-style. They refer to a part of a monologue and dialogue form due to be realized orally. It refers to public appearances by means of announcement, prepared speeches for different kinds and levels of foreign policy talks and activities.

\footnotetext{
${ }^{1}$ See further Janković, Diplomacy 1988, pages 109-110.
} 
Even a simple analysis of this style directs to set rules in morphological and syntactic forms and to certain linguistic standards and forms in use. It is partly about linguistic clichés and outcomes of a written material being by rule depersonalized with preponderance of so called nominal, due to the impression of the domination of nouns. The lack of the first and second person verb forms is noticeable, pointing to a preferable impersonal construction implying institutions, more rarely individuals. ${ }^{2}$ There are no firm barriers among these sub-styles considering the fact that they permeate and have numerous interactive mutual impacts. Diplomatic style bears no localisms, archaisms, vulgarities, augmentatives, including diminutives and non-standardized terms. As previously being stated, a florid style, by means of the existing demoralization is being abandoned, giving way to globalization technologies and linguistic standards but not to the detriment of the request for reduced writing and/or concise writing, in such a manner saying as much as possible. Clarity is a very significant feature of a diplomatic style. Conciseness and harmony are ranked among the most significant features in most of the functional styles. Not equal significance bears administrative-legal, scientific or literary-artistic style. The clarity in administrative-legal style is to be specifically emphasized. It bears no equal significance at the literary-artistic style where such clarity gives way to an artistic message ambiguity.

Diplomatic style is due to imply an explicit clarity reflecting in a correct choice of words and expressions, expressing a logical relation within the words in a sentence. According to some divisions accepted by a large number of authors, some of the aforesaid features could be ranked in the administrative-legal style, being used in state and social forms of communication. In a wider sense, diplomatic style belongs to it mostly because it implies correctness, clarity as previously having been stated. Besides, it also has a standardized form, seldom being abandoned. "A style means either a good way of writing and/or speaking or, however, such a style of speaking and/or writing, being characteristic to a literary epoch or a literary school, a writer or a literary work." ${ }^{3}$ However, in the course of time, the meaning of style is getting to be more substantial and richer. Different types of styles appear concurrently, showing essential differences in their specific features. ${ }^{4}$

${ }^{2}$ see for more Radekić: Stylistic and Rhetoric 2008

${ }^{3}$ Solar M, Theory of Literature, Zagreb 1976, pages 68,69,70.

${ }^{4}$ Solar M, compare op cit page 70.

In formal correspondence it is necessary to avoid abbreviations when it comes to subject names, especially international organizations names, as an acronym or an abbreviation in certain names might imply different meaning. The American President Ragan was considered as insufficiently educated when general international relations are in question. A great number of international relations analysts questioned his being a governor of California for eight years and a president of the USA for more than seven years, and with such a poor education enforcing foreign policy successfully and persistently. Doubtlessly, his language sometimes was inappropriate, even partly elementary.5 At the beginning of his mandate, he qualified the Soviet Union as a dissident empire inclined to any crime, lie, fraud in order to achieve their goal. He defined the Soviet Union as an evil empire, resorting to ethic qualifications, that not have ever been done by any American president before. 6 Such rhetoric by Regan caused numerous reactions by the side of those public figures who firmly believed in certain generally accepted principles. "They said apocalyptic symbolism to have been expressed by a primitive vocabulary."

Professor Hoffman from Harvard pointed to its militant style and condemned it as machismo, neo-nationalism and a form of fundamental reaction being not capable of offering the world which is loaded with vital problems, anything new or prosperous, not even in the USA which was facing economic problems not less than the Soviet Union.7

\section{Language in diplomacy}

Latin was the language of the written European diplomacy at the time of the Roman Empire, the Holly Roman Empire and the Catholic church. This language was dominant

5 see for more in Kissinger H. Diplomacy, Belgrade 1999, pages 680-682

6 see for more: Kissinger, op cit, page 682

7 see for more Hoffman S, Foreign Policy: What is to be done", New York Review of Books, 30April 1981. P. 33,37,39

in European countries diplomacy all the way to $17^{\text {th }}$ century. It was also in use later, especially on occasions when diplomats were not able to communicate in the language they both knew. 
Latin was used as Lingua franca especially throughout the Middle Ages. The Treaty of Westphalia from 1648 was written in that language. During the negotiations on the Treaty of Westphalia, the insufficient development of Latin proved itself. Its forms appeared to be so inappropriate that they often caused confusion. For that reason, they resorted to the use of French and English as their lexicon was more developed and standardized. 8 However, on the most of the palaces of European rulers, French was in common use. Diplomacy texts translation, explanation and interpretation may not always be reliable. In that context, a special interest for linguistic enthusiasts bears a case of the Treaty of Wuchale signed between Ethiopia and Italy in 1889 in Amharic and Italian language. According to the interpretation in Amharic, the Ethiopian king Menelic II was granted a large autonomy in foreign policy conducting. In the time to come, a protectorate over Ethiopia was established which proved to be consistent to the Italian translation of the above-said Treaty from 1889.

The fault might be found in linguistic formulations in Amharic, as a permissive clause was formed in that language, while in Italian it was formed as mandatory clause. Different interpretations and unfavorable consequences having occurred six years after the conclusion caused the war which Ethiopia won.g English, French and German are working languages on many sessions and meetings of different levels in the EU. English and French are official working languages. Thereat, it is necessary to emphasize English being in most frequent use regardless the fact that all the documents are to be correctly reinterpreted into all of 23 official languages in the European Union. The seriousness of an authentic creativity in translating is being manifested when correction beyond that frame are being done without a revision on negotiating about them. According to some estimates, at first translating treaties and different official acts appears to be a significant business. In the EU, translating official documents into all of the 23 official languages costs 300 million $€$ a year, which makes less than $1 \%$ of the budget. The significance of a correct translation is proved in the case of ratification delay due to a grammar error on a copy of the Treaty of the state of Ireland from 2012.

8 compare, Satow, s, Guide to Diplomatic Practice, New York 1979, p. 38.

9 see for more on the site:https://eu.wikipedia.org/wiki/treaty_of_Wuchale visit 27.10.2016. In the United Nations, six official languages are in use: Chinese (Mandarin), Arab, English, Russian, Spanish and French. English and French are two working languages in use. The use of French is being based on its historical role as a language of diplomacy. In the first part of $20^{\text {th }}$ century it was dominant as well. ${ }^{10}$ In the UN headquarters in New York, English is in advantage while in the UN headquarters in Geneva, French is preferred among the traditionalists. Treaties registered at the UN in UNTS edition are being translated both into English and French. It also relates to the documents enacted in the main bodies of the UN. In the Geneva headquarters both language versions of treaties and documents are equally authentic. It, in fact, ensures the base of a safe international system functioning.

\footnotetext{
${ }^{10}$ As early as the rule of Louis IV, a consolidation of French as a leading language, was noticeable in the Eurocentric diplomatic discourse of that time. Manly due to the merits of Richelieu, France became a leading country, entirely admitting the significance of sedentary diplomacy and partly mitigating the principle of peoples and their countries meeting at the top. The French Academy, having been founded by Richelieu himself, mostly studied languages, thus actively contributing to its perfection and improvement. The syntax of French is doubtlessly perfect. This feature makes this language, i.e. its statements precise. Those processes promoted French as the most suitable and the most perfect for the needs of diplomacy. This was the state until the beginning of $20^{\text {th }}$ century.

Thereat, however, it should be borne in mind, French, as a language of 74 million of authentic speakers can hardly keep its dominant role. According to a very spread opinion, it works as an anachronism. A reasonable doubt arises about the position of the languages such as Hindu, Portuguese and others with incomparably larger number of native speakers. In spite of it, survival of French as a working language, has been contributed to its very spread geographic diversification. Besides, as a diplomatic language, French has been in use for more than a hundred years in the international community. An added contribution to it is made by the fact that education of diplomats in France has been on the highest level. In the international organizations and in the diplomacy in general, French diplomats doubtlessly appear to be most qualified and most successful. ${ }^{11}$ However, English started overtaking the primate from French in $19^{\text {th }}$ century. Before that, in 1800 Lord Grenville introduced the practice of communicating in English with diplomats accredited on St James's court. At the time of the Congress in Vienna in 1815, Lord Castelrow, on behalf of the united military forces, communicated in English with foreign sovereigns and ministers.
} 
In the course of time, controversies arose due to the use of that official language, in other words, its primate was threatened. Even some British ministers of foreign affairs issued instructions to their diplomats to write in English. Such proceedings caused reactions in some cases. ${ }^{2}$ The Prussian government agreed to the refusal of Conte Berenstorff to receive a note of an English diplomat, written in English, estimating that the official communication is due to be in French. French is spoken in the international organizations "Doctors beyond borders" and in "The International Committee of Red Cross". It is also the language of traditionalists in diplomacy. Diplomats from French-speaking countries, regardless the fact that it is the language of their elites, doubtlessly make an important link in its deeper affirmation. The situation has changed in the contemporary world. French has not been any more representative. Officials and diplomats from the countries of Chinese, Russian and Arabic languages, do not regard their languages as successors of French. Apart from it, there has been an expansion of Spanish. Arab, Bengali and Spanish have considerably more authentic speakers.

\footnotetext{
${ }^{11}$ compare Janković B, op. cit. 1988, pages 110-111.

${ }^{12}$ Satow, s, op. cit. p 40.
}

For that reason, the existing system is regarded as a little dated and is to be improved. ${ }^{13}$ Diplomatic language implies the use of a tact, conciliatory style and settlement especially in stressful situations. ${ }^{14}$ A language is used to build with others, on the basis of his knowledge, cooperation and allow us have different forms of benefits, which is better than being alone, without the possibility of an essential communication with others. In diplomacy, it is a language of communication, negotiations and agreements formulating, summing, creating, conveying and recording facts, all of which largely being dependent on a language. Naturally, diplomacy is more often concerned about a message than a meaning. Obviously, the use of a language analysis in diplomacy leads to a better understanding of diplomatic functions and even processes with considerably safe indication, due to which, some diplomatic processes appear to be safer than others. By means of a careful and critical consideration of different aspects of diplomatic languages, we are able to, on the basis of clear, even on the basis of allusive messages of the global leaders, to increase the quality and the possibility of our own understanding the diplomatic communication. The usual contact between a head of mission and the Ministry for Foreign Affairs is being held by a written communication. A writ in the communication between the subjects in diplomatic relations is called a note. There is no general rule to define a form of a note. For that reason, there are different forms of it. The essence of an expression stated in words is due to have a tact and the facts expressed are due to be true and correctly and carefully selected. As for the contents, a note is a formal and personal letter, written in the first person. A form of a courteous addressing is also required. In French and English, in the diplomatic addressing a note is written personally. A verbal note is to be written in the third person. By the rule, it contains a direct addressing to the subject of the correspondence. Sometimes this term appears in the title of a Verbal note. ${ }^{15}$ Prosodic features of a language are very important for the reason that they might cause misunderstanding with unforeseeable consequences. Understanding an interlocutor is sometimes of a great importance for the continuation of a dialogue and for peaceful solution to problems.

\section{${ }^{13}$ see for more The Economist, 2 April 2013 \\ ${ }^{14}$ compare with Merriam Webster, $\mathrm{s}$ Colegiate Dictionary \\ ${ }^{15}$ see for more Satow, op cit p. 42}

Stressing certain sentence parts may have a multiple character in a diplomatic communication, as a necessity of a careful listening to an interlocutor is implied, above all from the reason of a cognitive dimension of a diplomatic affair. Therefore, good language skills of the language of communication are required. Sometimes nuances in language expression are required to convey a desirable message to an interlocutor. On the other hand, no matter how orally a message composed, there is always a danger of misunderstanding. It certainly has to be avoided. One of the ways is a parallel practice of a written form. In such a way, a message is exposed to numerous controls, doubtlessly contributing to its correct interpretation. Nowadays in a digital era a process of diplomatic messages conveyance has its technological innovations, contributing to the speed of communication but is often also a cause of misunderstanding. Sometimes other means, language surrogates, are used in those harmful consequences removal and even in explanation of those types of messages. Those non-verbal means as accompanying elements of speech, often contribute to understanding more than verbal components. 
Communicology as a science of the essence of communication tells how some gestures of diplomats can reveal real intentions of an interlocutor and/or to show the effects of many kinds, for example, those which might be called warning to those which might mean acceptance. Both are non-verbal but they contribute to the explanation of an interlocutor's messages of any kind.$^{16}$ Stratification of the language is a categorical plane covering a certain dynamic of language changes in general. That phenomenon leads to different sub-systems creation and confirms the fact that a language is not simple. It is dependent on many factors which make it more complex. Those forms of stratification originate from different causes and we can accordingly point to some of them, taking into consideration the facts of most importance for our work. Rhetoric appeared in the Ancient Greece as a learning about speaking. Later, it partly covered learning about a language. In a modern sense, there is an undivided opinion of speech cultivation being basically a rhetoric ideal. ${ }^{17}$ Linguistics as a science, its scientific dignity ows to Ferdinand de Sosier. After his scientific items and the works of numerous other authors, linguistics flourished. That made an impression, especially when it comes to a poststructuralist matrix that a developing matrix, based on linguistics is possible.

${ }^{16}$ The first international multilateral agreement, written in two languages (French and English) was A Versailles Peace Treaty, concluded during the peace conference after the First World War.

${ }^{17}$ v. Solar M,op. cit page 70

It was partly confirmed in anthropology, esthetics, sociology and politics. The fact is, linguistics strongly encouraged a science development in the area of semantic and communication processes of an anthropology entity. In our region a language of law in a certain way was subordinate to commands of a "political mind", as that language itself was not considered to contain any linguistic wealth. In fact it was basically about an obvious underdevelopment of linguistic dimensions of a legal language. For that reason, competences and awareness of the necessity in use of linguistics competences in studying legal phenomena, developed gradually."The language of law as a specific linguistic sub-system being in diplomacy, consists of a part of a general linguistic code and of a legal language, forming a nominal-legal code being a product of itself according to the rules of this code". ${ }^{18}$

Linguistic legal activity basically confirms a high level of a linguistic code and speech interdependence, as basically hardly any speaker deviates from the linguistic code adding to and/or enriching the meaning of some linguistic units. Sometimes it is about an essential changing, pre-structuring and/or other meanings destruction which often bring new contents. Indicative states of the language of law such as statements, descriptions, arguments in a sphere of diplomacy are due to be expressed clearly and to be true. At diplomatic speech consideration we should bear in mind the need for non-partial expressing, preciseness and a specific context and/or the words in use are due to be in a direct untransferable sense. Also a personal touch and phraseology without documentary grounds should be avoided. As a rule, a great importance bears widely present impersonality for the purpose of paying attention to almost inevitable objectivity ${ }^{19}$. The truth is simple and its expression produces a remarkable impression when it is clearly expressed deprived of rhetoric redundancies, especially of extensive explanations. In developed countries a successful diplomat is naturally very educated with a perfect knowledge of English and a solid knowledge of a language of the country of his office. In France foreign diplomats are tested while asking for a service in his country. In such a way his real influence in the country which sent him to a diplomatic mission is checked.

\footnotetext{
${ }^{18}$ Visković N, language of law, 1989, page 46.

${ }^{19}$ see for more Radikić V, Stylistics and Rhetoric, 2008, pages 164-177
}

If he is influential and may knock on many doors in his country, many doors will open in the host country of his office. On some occasions he may call a prime minister or a head of the state and talk to them especially if it is about a mutually important issue. ${ }^{20}$ In recent times an inappropriate language has been noticeable in appearance of some of the highest American statesmen. For example, a Vice President, Joseph Biden, in his speech in the ship yard in New Hampshire severely condemned monstrous murder of decapitating a journalist Sotloph by members of ISIL, stating among other things that "The USA is to be after them all the way to the door of hell." Without denying the legitimacy of the intervention emanation of evil in this case is of much deeper character than it could be concluded from the speech of a Vice President Biden. There is a proverb from a long time ago: "If one sows pumpkins with the devil, they will bash onto one's head. " 


\section{Conclusion}

According to some authors who paraphrase Schopenhauer's thought, "A style is the reflection of a person," diplomats are professionals who use language as the means of communication dependent on the specific occasions taking care of the interests of the subject of the international relations they represent. All of them use the language in their own manner in the developed states with recognizable foreign policy. For that reason it could be said that most of them had their specific working style. Additionally we must point that an appearance of a diplomat could not be successful beyond the frame of a clear and appropriate statement.

"The right thought does not exist without the right style." 21

${ }^{20}$ see: www.politika.rs/scc/članak/316358 “Foreign diplomats are polyglots for ours we don’t know” 2015

${ }^{21}$ see for more Schopenhauer A., About the style and writing 2016

It is obvious that an ambiguous style reflects a confusion of thoughts. A clear thought is shaped in appropriate non-contradictory and unambiguous statements. Specific features of a diplomatic language especially in the use among diplomats, indicate its abundance with lexicon, a large number of common phrases and stereotyped statement according to some opinions it is about a technicalized language which belongs to sort of lingua franca. On the other hand dominant are the opinions which indicate that is only about stylistic and linguistic characteristics of the communication of that profession. As a contribution to the second statement is the fact that there is a growing influence of globalism and changing circumstances in the international community which cause a change in grasping discretion, the inevitable characteristics of the traditional diplomacy. The tendency of deformalisation brings to the international scene a sort of a public diplomacy. That process, apart from the necessary democratization of diplomatic relations, often brings harmful and undesirable profanation of positive efforts of professional diplomats threatened by appearances of numerous commentators on omnipresent social networks. Or, as Turgeniev said: "The truth not spoken out at the right time can be worse than the worst lie."

\section{References}

1. Schopenhauer A., About the style and writing 2016.

2. Radikić V, Stylistics and Rhetoric, 2008.

3. Visković N, language of law, 1989.

4. Hoffman S, Foreign Policy: What is to be done", New York Review of Books, 1981.

5. Satow, s, Guide to Diplomatic Practice, New York 1979.

6. Kissinger H. Diplomacy, Belgrade 1999.

7. Solar M, Theory of Literature, Zagreb 1976.

8. Janković B, Diplomacy 1988.

9. Kissinger H.World Order, 2015.

10. Wilson P.The Thirty Years War:Europe,sTragedy,2009.

11. Vitgenstein L.Tractacus logicco-philosophicus 2013. 